investigator. By abbreviation and excision of mathematical deductions and numerical data, a very much smaller book has been prepared. It is easy to read, introduces the fundamental points, and can be heartily recommended as a sound, interesting, and adequate survey of elementary, theoretical colloid chemistry.

The subjects dealt with include the phenomena at interfaces (liquid/gas, liquid/liquid, solid/gas, solid/ liquid), such as surface tension, adsorption, capillaryelectric phenomena, and the properties of interfacial layers. The Brownian motion is discussed historically, and then are outlined the general properties of sols and gels, including the problem of the Liesegang rings. Brief accounts of clouds and smokes, and emulsions and foams, complete this useful introduction to the author's detailed book.

The reviewer takes exception to the statement (p. 165) relating to emulsions: "When one liquid is in considerable excess, it necessarily becomes the dispersion medium." The literature on colloidal chemistry records several examples of even 99 per cent. of one liquid being dispersed in I per cent. of another liquid. Also, both types of such concentrated emulsions are known, namely, oil-in-water and water-in-oil.

\section{William Clayton.}

Die Kriegsschauplätze I9I4-I9I 8 geologisch dargestellt. Herausgegeben von Dr. J. Wilser. (In r 3 Heften.) Heft I : Elsass. Von Prof. Dr. E. Kraus und Dr. W. Wagner. Pp. viii $+I_{54}+3$ Tafeln. (Berlin : Gebrüder Borntraeger, I924.) r 3 s. $2 d$.

KRAUs and Wagner's "Elsass" is the first in number of a series of monographs on the geology of some chief fields of the War. It shows the extent to which the German military staff used geological help. The series includes contributions to the geology of several areas in Europe of special interest which had been inadequately studied. Elsass, however, was geologically well known, though the province is tectonically complex because the Alpine movements have been superimposed on the older Variscan structure. The authors deal with the province in three divisions. In the North Vosges, pre-Cambrian gneisses and Cambrian rocks have both been folded by the Caledonian movements and succeeded by deposits ranging from middle Devonian to the Trias. In the Middle and South Vosges the gneisses are directly covered by Lower Carboniferous rocks; they have been altered by granites intruded during the Variscan disturbances which were followed by the deposition of the Permian and the Trias. The third region is the rift-valley of the Rhine with Oligocene, Pliocene, and Pleistocene deposits. The monograph contributes much fresh information, as well as summarising the evidence on these three important geological divisions.

Outlines of the Occurrence and Geology of Petroleum : an Introductory Handbook. By I. A. Stigand. With an Appendix on Geophysical Methods as applied to Oil-finding, by Dr. M. Mühlberg. (Griffin's Mining Series.) Pp. $\mathrm{x}+246$. (London: C. Griffin and Co., Ltd., I925.) Ios. 6 d. net.

Mr. STIGAND's handbook is one of the most generally satisfactory of the many smaller works now available regarding the geology of oil. In the discussion of the origin of petroleum he concludes that it comes from many different sources, but that the bulk of it is due to micro-organisms. The chapter on field structures is admirably clear and does not attach to anticlines the exaggerated importance often assigned to them. The author is optimistic as to the quantity of oil available; he gives a long list, stratigraphically arranged, of oil-bearing localities, and if most of them were to become important producers the future supply of mineral oil would be assured; but many of the places in the list will probably not yield oil in quantities of commercial importance. The author lays on the mineralogists the responsibility for the denial that coal is a mineral, whereas reference to the text-books by Miers, the two by Dana, and the handbooks of the Mineralogical Department of the British Museum would show that the mineralogists are not the authors of the definition which leads to that ludicrous conclusion. The most important part of the work is an appendix on oil-field survey by the torsion balance, by magnetic and electric methods, by the use of seismic and acoustic observations, and of radioactivity. There is a useful bibliography on this branch of oil prospecting:

Physical Chemistry: its Bearing on Biology and Medicine. By Prof. James. C. Philip. Third edition. Pp. vii +367 . (London : E. Arnold and Co., r925.) 8s. $6 d$. net.

THE principal new feature of the third edition of Prof. Philip's book is the increased attention which has been paid to problems relating to hydrogen-ion concentration -a purrely physical conception which has proved of such value in biological problems that its development has been very largely due to the intensive study of the phenomenon by physiologists. References to recent work have also been given, however, in other directions, and additional matter in reference to the properties of membranes has been inserted.

Distillation in Practice. By C. Elliott. (Chemical Engineering Library: Second Series.) Pp. 188. (London: Ernest Benn, Ltd., I925.) 6s. net.

Mr. ElliotT's monograph forms a useful supplement to his "Distillation Principles," recently noticed in NATURE. The first five chapters consider the operation of the fractionating column with mixtures of two components. Accounts are then given of distillation apparatus, and the cases of ethyl alcohol, petroleum, and coal tar are specially considered. References to recent literature are given.

Organic Syntheses: an Annual Publication of Satisfactory Methods for the Preparation of Organic Chemicals. Edited by Oliver Kamm, Roger Adams, H. T. Clarke, J. B. Conant, C. S. Marvel, F. C. Whitmore. Vol. 4. Pp. vii +89 . (New York: J. Wiley and Sons, Inc.; London: Chapman and Hall, Ltd., r925.) 7s. $6 \mathrm{~d}$. net.

THE fifth volume of this excellent series includes twenty-eight preparations, among which are cupferron, ketene, pyruvic acid, and triphenylmethane. It is indispensable to all who have to carry out preparative work in organic chemistry.

$$
\text { NO. 2920, VOL. I I 6] }
$$

